\title{
EFFECT OF DESCRIPTIVE FEEDBACK AND CORRECTIVE FEEDBACK ON ACADEMIC ACHIEVEMENT OF VII GRADERS IN MATHEMATICS
}

\author{
Ghazala Noureen* $^{*}$ \\ Mubashara Akhtar ${ }^{* *}$ \\ Riffat un Nisa Awan ${ }^{* * *}$
}

\begin{abstract}
Mathematics has become a universal language and a way of thinking especially due to the advancement in the electronic media. Effective teaching plays a vital role in the propagation of mathematical knowledge. Feedback strategies can be used to enhance mathematical understanding. Feedback process helps the students to acquire information about their existing achievement with respect to goals and help them to improve learning. This study was designed to explore the effect of descriptive feedback and corrective feedback on academic achievement of VII grade in mathematics. Only post-test control group design was used. There were three groups. Group 1 received descriptive feedback, group 2 received corrective feedback and group 3 served as a control group. All groups contained 53 students each. The results analysed indicated that descriptive feedback has more positive effect on students' achievements as compare to corrective feedback. Students taught through corrective feedback performed better than control group. Although, it is difficult to generalize the results of this study (issue of all experimental researches) but having support of literature it might be suggested that feedback is effective tool for the improvement of mathematics achievement of the students.
\end{abstract}

Keywords: Descriptive Feedback, Corrective Feedback, Academic Achievement.

\footnotetext{
* Assistant Professor, Institute of Education, Lahore College for Women University Lahore, Lahore, g_noureen@yahoo.com

${ }^{* *} \mathrm{Ph} \mathrm{D}$ Scholar University of the Punjab, Lahore

*** Associate Professor, Department of Education, University of Sargodha, Sargodha, riffarukh@gmail.com
} 


\section{Introduction}

History of mathematics as a subject of study is traced back to $6^{\text {th }}$ century BC. Since then mathematics passed through many phases of highly creative era to centuries of stagnation. Renaissance of mathematical development started in $16^{\text {th }}$ Century in Italy. Mathematics always remains the core subject in school curriculum. The prime objective of mathematics education in schools is the mathematisation of the child's thinking. Clarity of thought and pursuing assumptions to logical conclusions is central to the mathematical enterprise.

Many people think that mathematics is merely the acquisition of abstract skills due to its abstract nature. But this is also hard core reality that it is next to impossible to live an independent life without basic math skills. Children begin to learn about money in the early elementary grades, and in later grades can calculate percentages and fraction. People need to have these skills in order to follow a recipe, evaluate whether or not an item on clearance is a good deal and manage a budget among other things.

One can do well in various routine activities without knowing reading and writing but one cannot pull on without learning how to calculate and count (Ali, 2008). A person belonging to any class of the society utilizes knowledge of mathematics in one form or the other. Mathematics is actually related to each aspect of human life. It remains same in the whole universe, every-time and every-where. It is not changeable. Thus, Mathematics is characterized (Mishra, 2008) as:

- $\quad$ The underpinning of the scientific and technological study

- $\quad$ Provide ways towards real situations

- A gizmo for solving the problems

- A tool of self-evaluation

Mathematics education in our schools is affected by many factors which deteriorate the quality of learning. The major areas which need to be addressed are a sense of fear and failure regarding mathematics, curriculum, crude methods of assessment, lack of teacher preparation and support and inappropriate teaching methods.

There are many types of feedback strategies teachers used in their classes as; descriptive feedback, evaluative feedback, corrective feedback, motivational feedback, elaborative feedback etc. This study is designed to investigate the effectiveness of descriptive and corrective feedbacks while teaching mathematics.

Descriptive feedback is constructive helpful information that clearly addresses answers. It is the learning through coaching instead of critiquing. This information makes students to reflect and is given to 
students orally. When teacher use assessment for learning, students get benefit from the descriptive feedback. It enables the students to learn through assessment process. In a differentiated classroom setting descriptive feedback is essential since it provides specific guidance to students to improve their learning and performance (Marzano, Pickering and Pollock, 2001). Descriptive feedback is implemented in various ways through: self and peer feedback, criterion feedback, via modelling and via opportunities.

According to Ohta, (2001) corrective feedback is a kind of repair. In corrective feedback teacher points out the mistakes of their students and correct them without giving any explanation or any further elaboration to them. Mostly corrective feedback and its types are used in different languages context to correct the mistakes of the students. In mostly research studies, corrective feedback is named as error correction feedback. Corrective feedback helps the learners to improve their learning skills and also helps them to understand different concepts correctly. Therefore, corrective feedback is an integral part to cover the learning gaps of individuals. Different factors such as; language, attitude, aptitude, memory, motivation, belief, and interest of the learners affect the way of the feedback they get.

Effective teaching plays a vital role in the propagation of mathematical knowledge. Traditional approaches of teaching students are not adequate to transmit the knowledge to the students and to motivate them. Therefore, it is imperative to familiarize students with new developments, procedures, techniques, and modern methods in all domains of life especially in teaching-learning situation to motivate, and encourage the students. Feedback strategies can be used in different situations especially in any teaching-learning situation.

This study used descriptive and corrective feedback techniques as two levels of independent variable and tried to investigate the effect on achievement (dependent variable) of students in mathematics. It was hypothesized that descriptive and corrective feedback techniques effect positively the academic achievement of mathematics students.

\section{Methodology}

This study is quantitative in nature and experimental method was used. Only post-test control group design was used. Three enact groups were taken because school administration did not allow to reshuffle the existing sections. 
Two feedback techniques were applied to two groups and one group served as controlled group. Techniques were assigned randomly to three groups. The duration of experiment was twelve weeks. Group received descriptive feedback was named as G I, group received corrective feedback G II and controlled group as G III. After twelve weeks post-test was conducted to investigate the difference among three groups.

\section{Participants}

In the current study, one public sector school was selected as the sample. There were 159 students who were studying in VII grade. These 159 students were divided into three groups each group consisted of 53 students. Intact groups were selected and then randomly assigned to subgroups i.e. Group A, Group B and Group C. Treatment was randomly assigned to the groups.

\section{Instrumentation}

Achievement test constructed as post-test is based on mathematical framework of National Assessment of Educational Progress (NAEP) and National Curriculum. According to this framework the curriculum of mathematics comprised of total five standards.

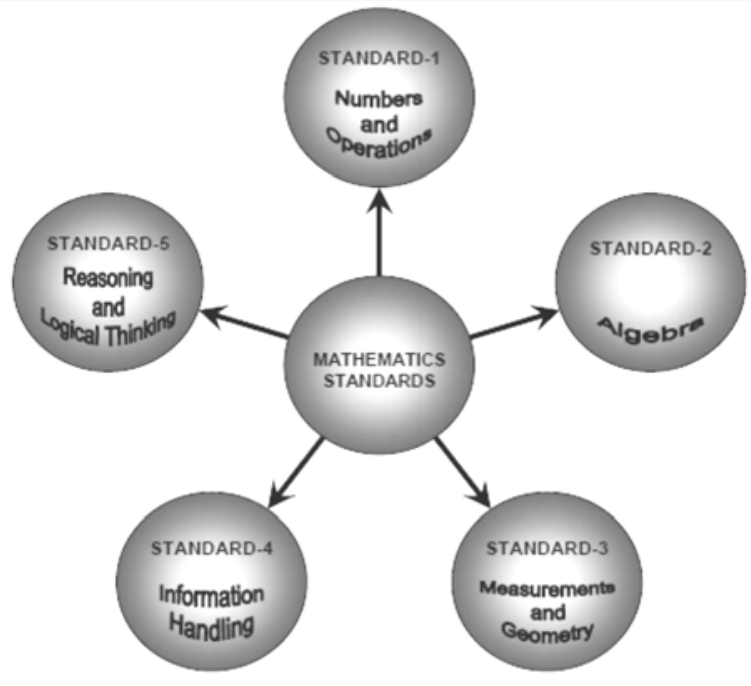

Sixty items (MCQ's) were constructed. The test was delimited to the eight chapters $(1,2,4,5,8,9,10,11)$ of the Mathematics text but covered all three aspects i.e. arithmetic, algebra and geometry. Test was constructed against Student Learning Outcomes (SLO's) mentioned in National Curriculum document. The test comprising of 60 MCQ's have 9 items of information, 
nine of understanding, thirteen of applying, ten item of analyzing, 11 of evaluating and nine items to assess the creative ability.

\section{Pilot Testing of Achievement Test}

Test was administered to 250 female students of class VII of session (2013-2014). To evaluate the date 'ConQuest' ageneralized item response modeling software (Wu, Adams, \& Wilson, 1997) was used.

IRT

Range Value of $\mathrm{b}$ is $-3-+3$

Range of means square $0.8-1.2$

Range of outfits means square $0.8-1.2$

\author{
Classical Theory \\ D-Index $0.3-0.8$ \\ D-Index $0.2-0.8$ \\ Point Bi-serial greater than 0.8
}

Thirty eight items met the above mentioned criteria and from these 38 items 30 items were selected for the final test by considering the time limit and to balance the table of specifications.

\section{Reliability}

The reliability of the achievement test was determined through test - retest method. The reliability was .80 .

\section{Procedure of the Study}

The lessons plans for this study were prepared by consulting textbook of mathematics grade VII, in consultation with the subject specialists of Science and Mathematics. The teaching material / teaching aids were used for teaching mathematics through feedback techniques and traditional lecture method as given below. Seventy two lesson plans for each group were prepared. Descriptive feedback sheet was given on daily basis and teacher gives their description on the sheets by correcting the mistakes of the students. Through this students learn their mistakes and the next time try to overcome it. Similar sheets were given to group II and teacher just corrects their mistakes without descriptions. Group III was taught as normal class. Weekly tests were taken from all three groups. After 12 weeks a post-test was administered.

For giving the descriptive feedback to the students a feedback sheet was used with complete description and solution of the problem/mistake. Experimental group 2 was also given the treatment in which this group was taught by corrective feedback techniques. These techniques were used one by one on altering days. For giving the corrective feedback to the students a feedback sheet was used with complete description of the mistake type. This helps the students to correct their mistake by their self. This practice as carried out for twelve weeks. 
Seventy two periods of each group is taken (Total=216) and then post-test of academic achievement were taken to find out the difference in student's performance. No discipline problem arose during this span of time. All the instructions were delivered to experimental and control groups by the researcher. The principals and teaching staff extended full cooperation and coordination during the study period.

\section{Data Analysis}

History and maturation were controlled using three groups. Testing, regression and instrumentation become irrelevant due to absence of pre-test. Mortality could be a threat but fortunately none of the participant left study. Selection interaction is the threat of this study because intact groups were used. Multiple treatment interference is irrelevant while selection treatment interaction was a threat. All threats to internal validity were controlled using different techniques.

\section{Results}

The main objective of this research study was to compare the academic achievement of group I and II who received two different types of feedbacks and group III without any feedback. To measure their academic achievement, tests were administered to the students. $T$-test was used to measure the significant difference between the groups.

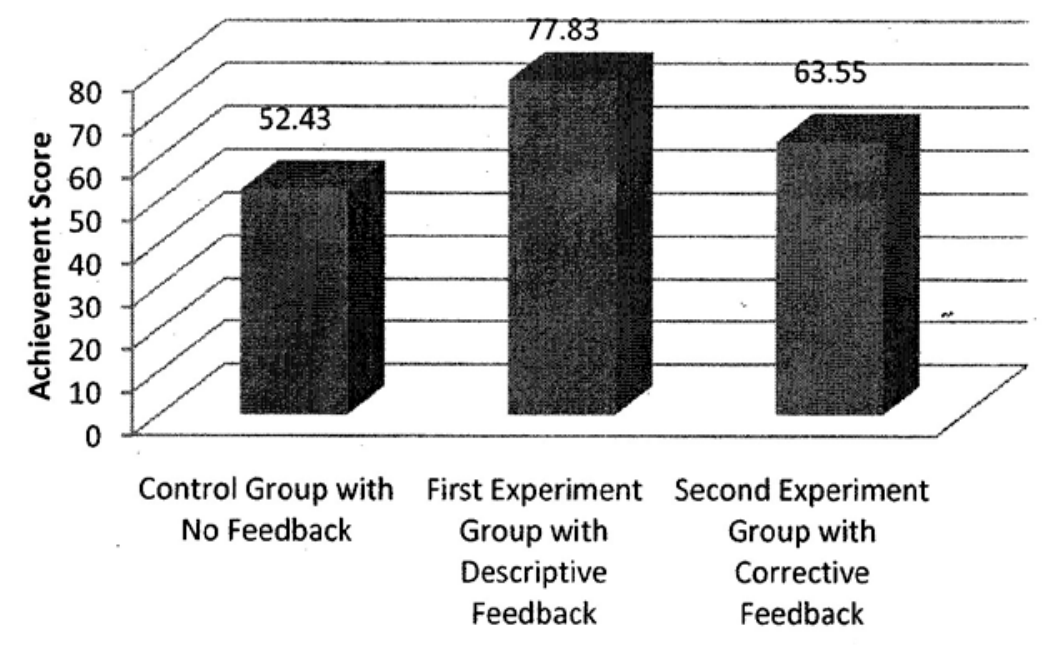

Figure 1. Comparison of effect of feedback type on student achievement 
The above figure shows that the achievement of Group I, is better than remaining two groups.

Table 1

Comparison between Group-I \& Group III on the basis of Post-test scores

\begin{tabular}{lcccc}
\hline \multicolumn{1}{c}{ Groups } & t-value & $d f$ & $p$ & $\begin{array}{c}\text { Mean } \\
\text { Difference }\end{array}$ \\
\hline $\begin{array}{l}\text { Group-I } \\
\text { Group-III }\end{array}$ & -18.115 & 104 & .000 & -10.9056 \\
\hline
\end{tabular}

Table 1 shows that group I and group III are significantly different and the value of $t(104)=18.115, p=0.000$ shows the null hypothesis stating no significant difference in the achievement scores of group I and group III was rejected. The achievement score of students of group 1 is significantly greater than group III.

Table 2

Comparison between Group-I \& Group-II on the basis of Post-test Scores

\begin{tabular}{lcccc}
\hline \multicolumn{1}{c}{ Groups } & $t$-value & $d f$ & $p$ & $\begin{array}{c}\text { Mean } \\
\text { Difference }\end{array}$ \\
\hline $\begin{array}{l}\text { Group-I } \\
\text { Group-III }\end{array}$ & 4.861 & 104 & .000 & 4.90566 \\
\hline
\end{tabular}

Table 2 indicates that group-I and group II are significantly different. The value of $t(104)=4.861, p=0.000$ shows the null hypothesis stating no significant difference in the achievement scores of group-I and groupII was rejected.

Table 3

Comparison between Group-II \& Group III on the basis of Post-test Scores

\begin{tabular}{lcccc}
\hline \multicolumn{1}{c}{ Groups } & $t$-value & $d f$ & $p$ & $\begin{array}{c}\text { Mean } \\
\text { Difference }\end{array}$ \\
\hline $\begin{array}{l}\text { Group-I } \\
\text { Group-III }\end{array}$ & -6.085 & 104 & .000 & -6.00000 \\
\hline
\end{tabular}

Table 3 indicates that group II and group III are significantly different and the value of $t(104)=-6.085, p=0.00$ 0shows that the null hypothesis stating no significant difference in the achievement scores of group II and group III was rejected. 


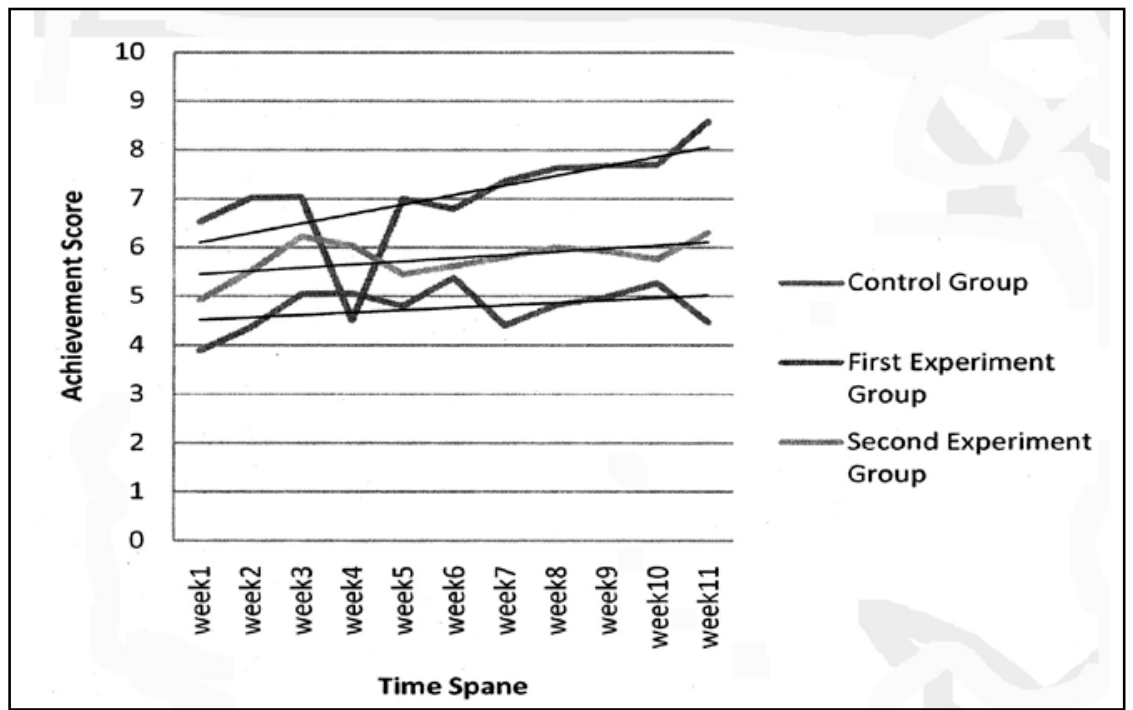

Figure 2. Effect of feedback strategies on student achievement

Above graph shows the effect of descriptive feedback and corrective feedback on students' achievement during a specified time period. It explores that both feedback types has positive relationship with time. Since trend line of descriptive feedback group is steeper than other trend lines so it may conclude that descriptive feedback has much better (from $65.3 \%$ to $85.8 \%$ ) positive effect on students' achievement than corrective feedback (from $49.2 \%$ to $63.0 \%$ ) over time.

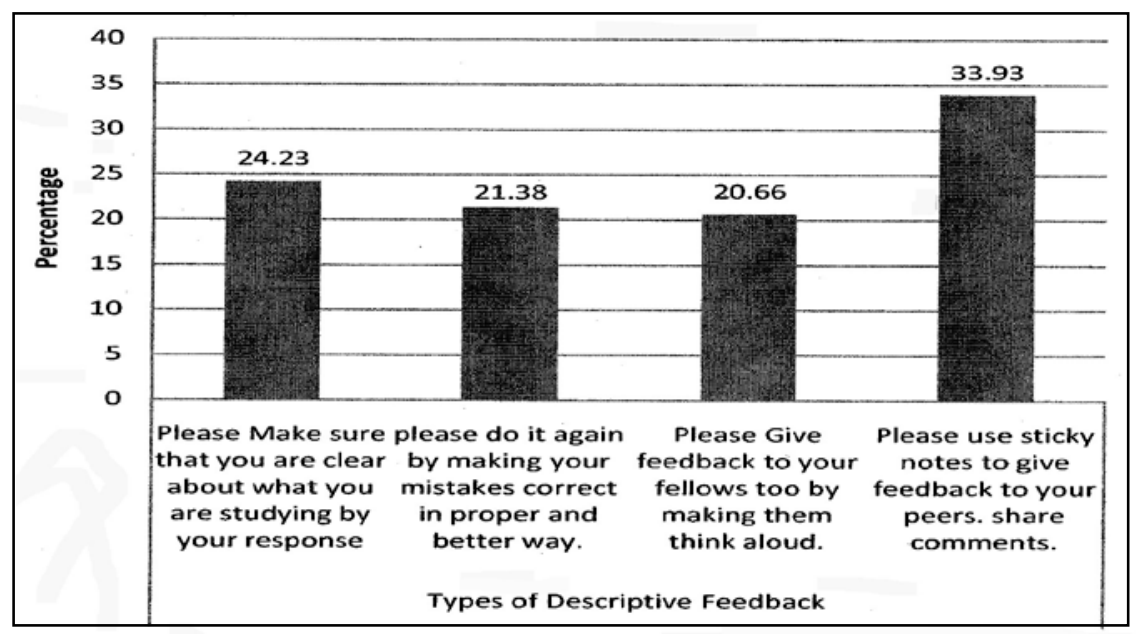

Figure 3. Difference between the effectiveness of types of descriptive 


\section{Feedback}

Above figure indicates the effectiveness of descriptive feedback types: i.e. Criterion feedback has $24.23 \%$ effect on improving student's achievement. Modeling has $21.38 \%$, while opportunities has $20.66 \%$ and self and peer assessment has $33.93 \%$ effect on student's academic achievement. Among all, taking sticky notes to give feedback to peers is most effective than other three descriptive feedback types.

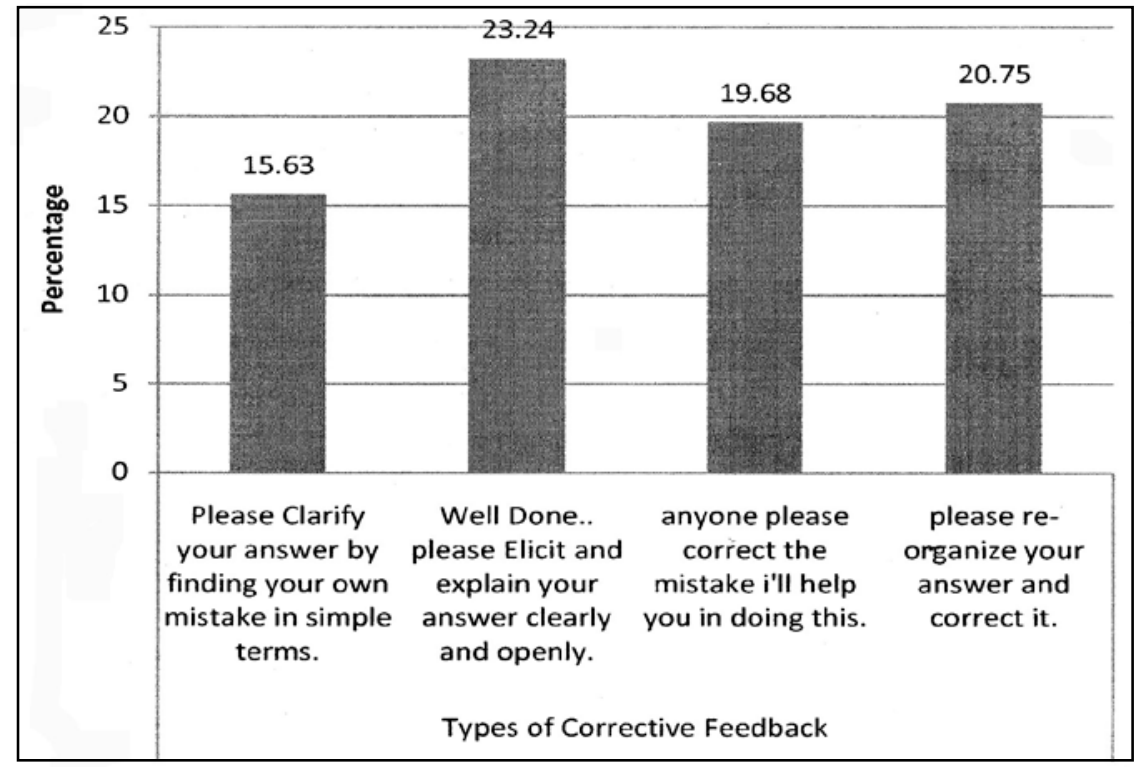

Figure 4. Difference between the effectiveness of types of corrective

\section{Feedback}

Above graph explores the effectiveness of corrective feedback types: i.e. Clarification request has $15.63 \%$ effect on improving student's achievement. Elicitation has $23.24 \%$, meta-linguistic clues have $19.68 \%$ and recast has $20.75 \%$ effect on student's academic achievement. Among all, asking students to elicit and explain their answers clearly and openly is most effective than other four corrective feedback types.

\section{Discussion}

In teaching learning situation feedback is a process of identification of strengths and weaknesses of students. The main objective is the rectification of weaknesses. It is very important for all to 
know about their performance that how well they are doing in it. It also helps the students to identify and overcome their mistakes. It is important for teachers to monitor students' learning and give them feedback. Feedback can be given to individuals, in a form of group, or to the full class. It will be more effective if the whole class can share in the monitoring.

This research study was planned to find the effect of corrective feedback and descriptive feedback on academic achievement of VII grade students. The main objective of this study is to explore that how feedback strategies affect the academic achievement of the students. Two feedback strategies i.e. descriptive feedback and corrective feedback are used in this study. Findings reflect that feedback enhanced students' achievement. This is supported by the findings of Kim, (2004), Chaudron, (1986) Carroll, Roberge \& Swaen, (1992) that the students who received feedback performed better as compare to the students having no feedback.

Findings of this research study also revealed that descriptive feedback is more effective than corrective feedback and traditional methods. Bangert-Downs, et al, (1991) found that descriptive feedback help to improve students' learning and to understand the subject's language in a better way.

The initial working definition of corrective feedback was as a type of repair. Repair is a process in which trouble sources in interaction are resolved. Repair is initiated by the self or another when the trouble source is identified, and may be brought to completion by the self or another. Research literature on repair in classrooms overlaps with work in corrective feedback but is broader in scope. Corrective feedback research traditionally looked at narrower slice of repair phenomena, primarily focusing on other originated, other-repair, and other-initiated, self-repair and limiting the type of trouble sources examine. In other words, corrective feedback has been viewed as other- initiated repair (Ohta, 2001). Lyster and co-researchers (1997) in many of their publications, observed the effect of corrective feedback on students. They examined the relation between different styles of correctivefeedback and its application. He analyzed that student renovation of grammatical and lexical errors were more elicitation, clarification request and meta linguistic clues than other types, in specific recast.

Corrective feedback happened mostly in explicit languages frameworks. Modified and uptake outputs were more likely to occur in 
language of explicit contexts. Corrective feedback, approval \& improved outputs were less common in management. It is obvious, then, that approval differs depending on different macro factors such as: instructional surroundings and micro-factor such as participating structure of class and determination of explicit interaction (Ellis, 2012).

Some studies (Sheppard, 1992; Robb, Ross \& Shortreed, 1986; Kepner, 1991) tried to investigate the kind of feedback that improves accuracy of students and anticipated that there was no significant difference between these two types of feedback. Although Fathman and Whalley (1990) documented that students who received oral feedback made some grammatical errors.

Ammar and Spada (2006) investigated that corrective feedback improved student's grades and also found that the recast is better way to give corrective feedback to students than others while results of this study reveals that elicitation is the best approach of corrective feedback as compared to other approaches. On the basis of the results of this study, it can be safely concluded that descriptive feedback and corrective feedback are the best tools to enhance students' learning and achievement.

\section{Conclusions}

After data analyses, following conclusions are drawn:

1. It is concluded that the students who received descriptive feedback perform significantly better than students who were given corrective feedback.

2. Students who received corrective feedback perform significantly better as compare to students without any feedback.

3. It is also inferred from the analysis that elicitation is the best approach of corrective feedback as compared to other approaches.

4. It is also inferred from the analysis that Self and Peer assessment is the best approach of descriptive feedback as compared to other approaches. 


\section{REFERENCES}

Ali, A. A. (2008).Perceptions, Difficulties and Working Memory Capacity Related to Mathematics Performance, MSc thesis, University of Glasgow.

Ammar, A., \& Spada, N. (2006).One size fits all? Recasts, prompts and L2 learning. Studies Second Language Acquisition, 28, 543-574.

Arends, R. I. (2004). Learning to Teach. (6th ed). New York: McGraw Hill Company. Bangert-Drowns, R., Kulik, C., Kulik, J., \& Morgan, M. (1991).The instructional effect of feedback in test-like events. Review of Educational Research, 61(2), 213-238.

Bangert-Drowns, R. L., Kulik, C. C., Kulik, J. A., \& Morgan, M. (1991).The instructional effect of feedback in test-like events. Review of Educational Research, 61, 213238.

Carroll, S., Roberge, Y., \& Swain, M. (1992).The Role of Feedback in Second Language Acquisition: Error Correction and Morphological Generalization. Applied Psycholinguistics, 13, 173198.

Carroll, S., \& Swain, M. (1993).Explicit and Implicit Negative Feedback. An Empirical study of the learning of linguistic generalization. Studies in Second Language Acquisition, 15, 357-386.

Chaudron, C. (1986). Teachers Priorities in Correcting Learners Errors in French Immersion Classes. In R. R. Day (Ed.), "Talking to Learn": Conversation in Second Language Acquisition. Cambridge, MS: Newbury House.

Chun, A., Day, R. R., Chenoweth, A., \& Luppescu, S. (1982). Errors, interaction, and Correction: A Study of Native-Nonnative Conversation. TESOL Quarterly, 16, 537-547.

Ellis, R. (2012). Language Teaching Research and Language Pedagogy, Oxford: Library of Congress

Fanselow, J. (1977). The treatment of error in oral work. Foreign Language Annals, 10, 583-593.

Fathman, A., \& Whalley, E. (1990).Teacher Response to student writing: Focus on form versus content. In B. Kroll (Ed.), Second language writing: Research insights for the classroom (178-190). Cambridge: Cambridge University Press.

Frey, N., \& Fisher, D. (2011).The formative assessment action plan: practical steps to more successful teaching and learning. (pp. 27-33, 71-83). Alexandria, VA: ASCD.

Kepner, C. G. (1991). An Experiment in the Relationship of types of written Feedback to the development of second-language writing skills. Modern Language Journal, 75, 305-313.

Kim, J. H. (2004). Issues of Corrective Feedback in Second Language Acquisition. Working Papers in TESOL \& Applied Linguistics, 4 (2), p.1-24. 
Lyster, R., \& Ranta, L. (1997).Corrective feedback and learner uptake: Negotiation form in Communicative Classrooms. Studies in Second Language Acquisition, 19,37, 66.

Marzano, R., Pickering, D., \& Pollock, J. (2001).Classroom instruction that works: Research based strategies for increasing student achievement. Alexandria: Association for Supervision and Curriculum Development.

Mishra, D.L. (2008). Teaching of mathematics. New Delhi: S.B. Nangia

Nassaji, H. (2009). Effects of Recasts and Elicitations in Dyadic Interaction and the Role of Feedback Explicitness. Language Learning, 59, 411-52.

Ohta, A.S. (2001). Second Language Acquisition Processes in the Classroom. New Jersey: Erlbaum Publishers.

Richard, W. (1996).Strategy as practice. Long Range Planning, 29, 5, 731-735.

Robb, T., Ross, S., \& Shortreed, I. (1986). Salience of feedback on error and its effect on EFL writing quality. TESOL Quarterly, 20, 83-93.

Sheppard, K. (1992). Two feedback types: Do they make a difference? RELC Journal, 23,103-110.

Wu, M.L., Adams, R.J., and Wilson, M.R. (1997). ConQuest: Multi-Aspect Test Software, [computer program] Camberwell: Australian Council for Educational Research. ACER ConQuest: Generalized Item Response Modelling Software ... Rasch Measurement Transactions, 1999, 13:3 p. 711

Received on: July 15, 2015

Revised on: December 1, 2015

Accepted on: December 10, 2015 